\title{
A Novel Low Cost UWB Antenna for Early Breast Cancer Detection
}

\author{
Amal Afyf ${ }^{1}$, Larbi Bellarbi ${ }^{1}$, Anouar Achour ${ }^{1}$, Fatima Riouch $^{2}$, Abdelhamid Errachid ${ }^{3}$ \\ ${ }^{1}$ Electrical Engineering Research Laboratory (LRGE)/ENSET-ENSIAS, University Mohammed V, Rabat, Morocco \\ ${ }^{2}$ SRTS Laboratory, National Institute of Post and Telecommunications (INPT)), Rabat, Morocco \\ ${ }^{3}$ Institute of Analytic Sciences (ISA), Lyon University, Lyon, France
}

Email address:

afyf.amal@gmail.com (A. Afyf), 1.bellarbi@um5s.net.ma (L. Bellarbi)

\section{To cite this article:}

Amal Afyf, Larbi Bellarbi, Anouar Achour, Fatima Riouch, Abdelhamid Errachid. A Novel Low Cost UWB Antenna for Early Breast Cancer Detection. American Journal of Electromagnetics and Applications. Vol. 3, No. 5, 2015, pp. 31-37. doi: 10.11648/j.ajea.20150305.11

\begin{abstract}
Detect breast cancer in early stages, ensure a comfortable and cheap diagnostics in order to reduce women mortality, are the challenges of this paper. A compact ultra wideband (UWB) Planar antenna for Microwave thermography system is designed and simulated using two commercial software, CST Microwave Studio and HFSS simulators.
\end{abstract}

Keywords: Early Breast Cancer Detection, Reduce Mortality, UWB Planar Antenna, Microwave Thermography, CST MWS, HFSS

\section{Introduction}

Breast cancer is the second leading cause of women's mortality [1]. Early detection increases the chances of successful treatment. The capabilities of current medical devices to detect breast cancer are agreeably insufficient for society's needs. The detection methods to reveal the tumor structure are divided in two main categories: non-invasive and invasive methods. The main invasive methods that use the breast exposure to electromagnetic, magnetic, ultrasound fields or radioactive tracers are: Conventional $\mathrm{X}$ ray mammography, Full Field Digital Mammography, Ultra-sonography, Impedance Tomography, Nuclear Tomography and Ductography, Scinti-mammography, Magneto-mammography, diffuse light imaging and Laser Breast Scanner [2-6]. The noninvasive that use specific fields of the anatomic structure as well as certain mechanical properties are: Infrared Thermography (IR) and Microwave Radiometry (MR). The Noninvasive techniques are preferred because they don't use ionogene radiation, it could be made as often as necessary and it doesn't seem to be harmful for the patient. Thermographic imaging uses the radiation emitted by the biological structures themselves within the microwave range Fig.1, according to the radiation laws of electromagnetic waves. Compared with infrared thermography the microwave radiometry allows the detection of depth malignant structures because the microwaves has a greater wavelength and are less absorbed by the tissue traversed from the tumor to the surface. The determination of thermal radiation is a measurement of tumor activity [7], providing date beyond the physical parameters.

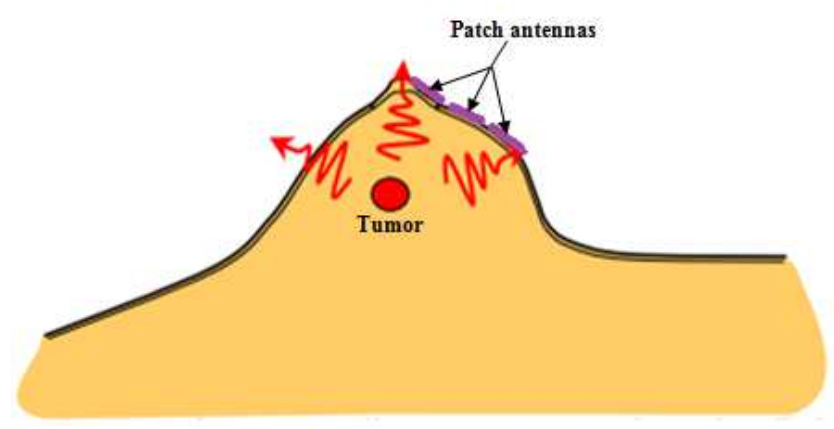

Figure 1. Microwave thermography principal.

Moreover patch antennas are regarded as one of the key components in ultra wideband (UWB) communication systems which have attracted significant research power in the recent years. A feasible UWB antenna should possess a good performance in term of return loss (S11), voltage standing wave rate (VSWR), radiation pattern and gain. Thus it's commonly known that the patch/microstrip antenna suffers from narrow impedance bandwidth. For the past few years, many researchers have investigated this phenomenon for the purpose of overcoming it. Meanwhile, there are many techniques which possess different structures are capable of 
achieving broadband antennas, such as coplanar coupled feed [8], aperture coupled feed [9, 10], Open square loop patch [11], slot-coupled patch [12], proximity fed square ring patch [13], E-shaped patch [14], coupled annular ring antenna [15], slotted rectangular patch [16], H-shaped antenna [17], meandering probe-fed patch [18], E-H shaped patch [19], Wshaped patch [20], U-shaped patch [21], and stack patch [22]. By using these techniques, a wider impedance bandwidth of up to $50 \%$ has been achieved. Suspended plate antenna (SPA) has been used as an alternative in designing antennas for low profile, compact, and wideband applications [23, 24]. Generally, the radiating plate is placed in parallel with the ground plane at a certain height. An air or foam layer with a low dielectric constant is used as a medium between the plate and ground plane [25].
Based on the above references and as the first component in microwave radiometry system, fig. 2, we propose a simple planar UWB antenna with a wide pentagon slot in the radiator and a reduced ground-plane with a T-slot. As described in subsequent sections, the initial antenna and optimization were carried out using CST Microwave Studio [26], a commercial electromagnetic simulator, and the Ansoft simulation software high-frequency structure simulator HFSS [27].

So the challenge of our study is the conception of a highperformance antenna, which operates at S-band (2-4GHz), to connect it with the other radiometer components in order to reconstruct the thermal images. This antenna can be placed in contact with breast to give us a clear insight for the studied concept (internal breast heat).

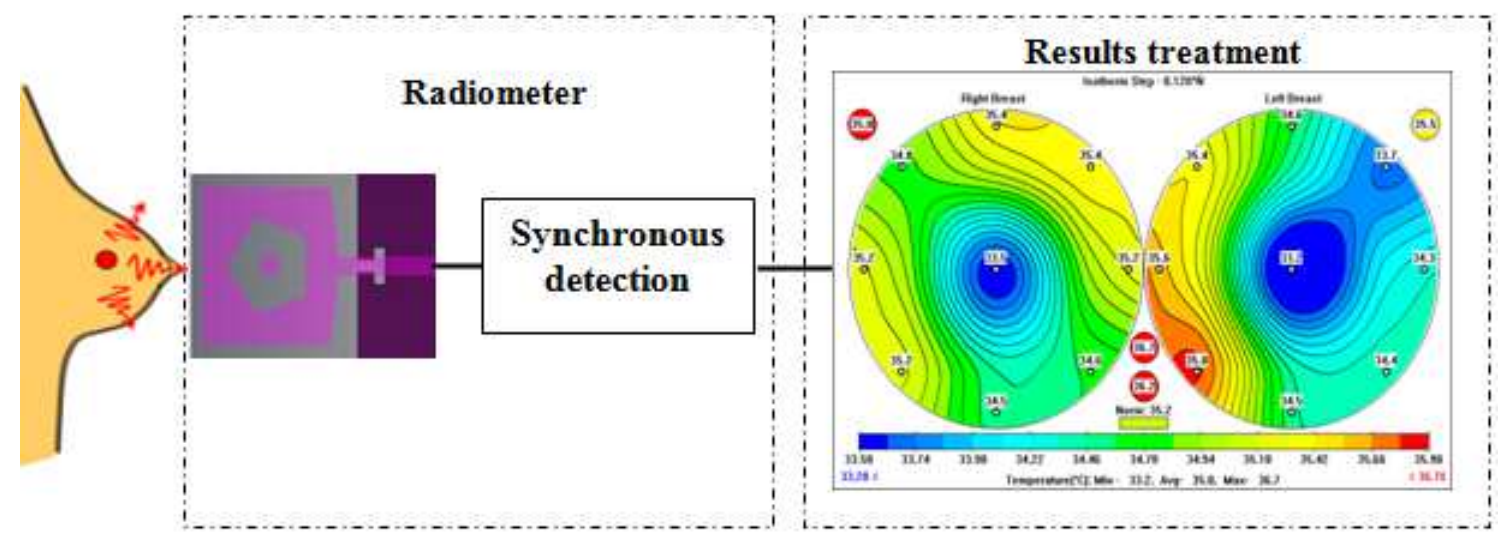

Figure 2. Breast cancer detection steps.

\section{Antenna Design Process}

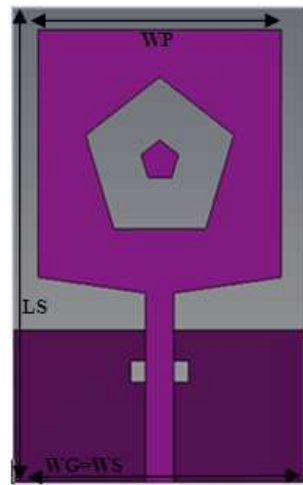

(a)

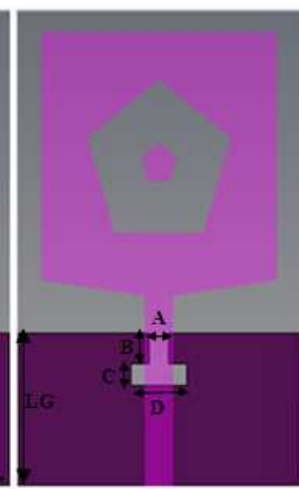

(b)
Figure 3. The proposed antenna (a): Front view (radiator), (b): Back view (gound plane).

The proposed shape of the structure shown in Fig. 3.a consists on a microstrip antenna with a UWB radiation properties, fed by a microstrip line, which is printed on a FR4 substrate of a thickness of $1.58 \mathrm{~mm}$, having permittivity constant $\mathcal{E}_{\mathrm{r}}=4.4$, loss tangent $\tan \delta=0.0019$. The width $W_{F}$ of the microstrip feed line is fixed at $3 \mathrm{~mm}$, and the length $L_{F}$ is at $18 \mathrm{~mm}$, which ensure a characteristic impedance of $50 \Omega$. The geometry of the antenna is a rectangular patch with a width $W_{P}$ and a wide pentagon slot.

On the other side of the substrate, a reduced ground plane with a T slot of width $W_{S}$ and length $L_{G}$ is placed as shown in Fig. 3. b.

Hence the main goal is to design an antenna with UWB radiation. We need to apply some techniques to improve the impedance bandwidth performance. We have started from a simple square patch (Antenna a), and by adding a wide pentagon slot we obtained a slotted antenna (b), then antenna (c) is achieved by introducing a T-slot in the reduced ground plane as shown in Fig.4.b. All physical dimensions of the proposed antenna are summarized in the Table 1.

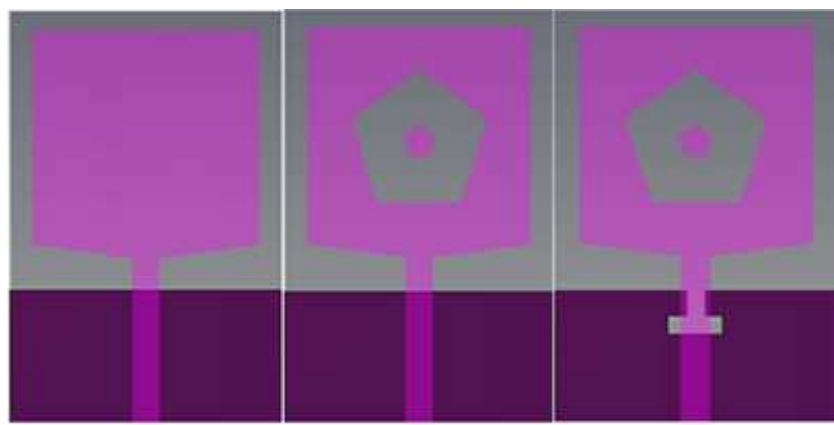

(a)

(b)

(c)

Figure 4. (a) The antenna with a simple ground plane (b) antenna with $T$ slot in the ground plane. 
Table 1. Physicals dimensions of the proposed antenna.

\begin{tabular}{llllll}
\hline Parameters & Descriptions & Dimensions $(\mathbf{m m})$ & Parameters & Descriptions & Dimensions $(\mathbf{m m})$ \\
\hline LS & Substrate Length & 45 & WG=WS & Ground plane width & 30 \\
WS & Substrate width & 30 & TM & Metal thickness & 0.035 \\
LP & Patch length & 25 & S & Inner radius & 2 \\
WP & Patch length & 25 & R & Outer radius & 4.5 \\
LG & GP length & 14.5 & T Slot & A $\times$ B and C $\times$ D & $2 \times 3$ and $6 \times 2$ \\
\hline
\end{tabular}

\section{Simulation Results \& Discussion}

In order to optimize the performances of the antenna obtained by using the CST simulation tools, we have added a T-slot in the ground plane Fig.4.c. This modification has turned the antenna (a) from an UWB antenna less matched, which has a bandwidth from $1.98 \mathrm{GHz}$ to $4.56 \mathrm{GHz}$ with return loss less than $-10 \mathrm{~dB}$ (VSWR $<2$ ), to another antenna (b) well matched especially at $3.3 \mathrm{GHz}$ and it has a bandwidth from $2.01 \mathrm{GHz}$ to $4.4 \mathrm{GHz}$ with a minimum of $-23.36 \mathrm{~dB}$ at 3.64 GHz (VSWR <2) as shown in Fig.5-6.

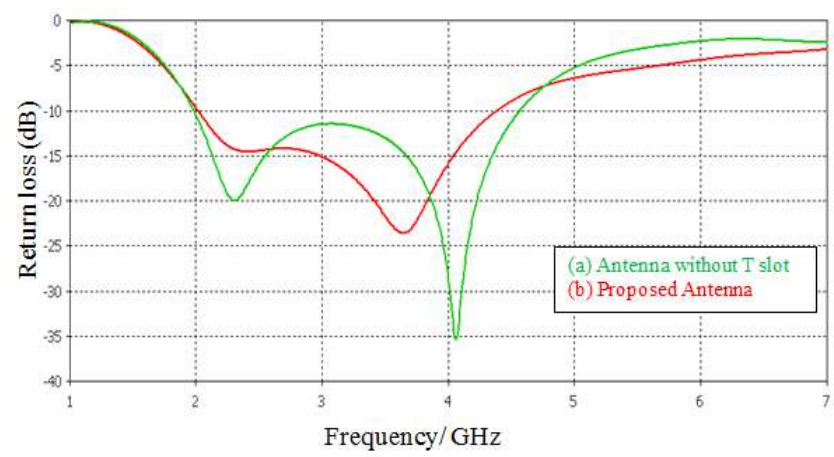

Figure 5. Simulated return loss of the two antenna structure.

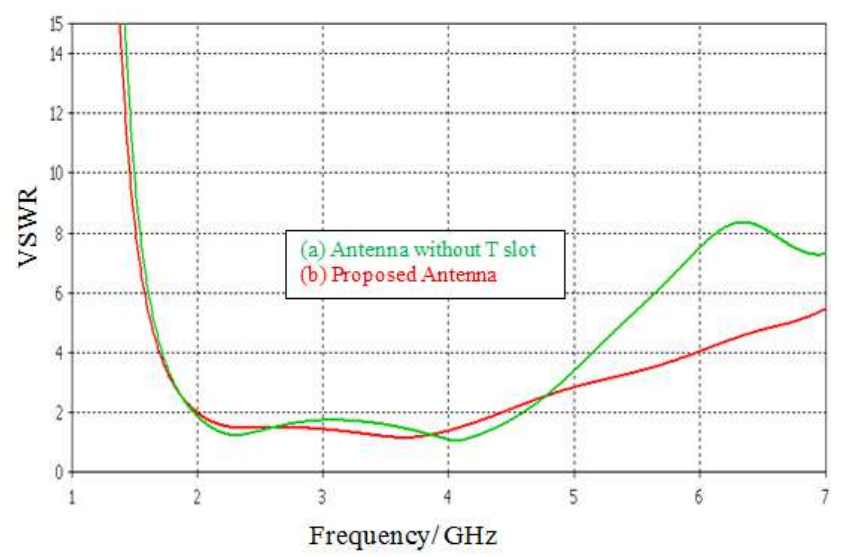

Figure 6. Simulated VSWR of the two antenna structure.

In addition to CST MWS simulator, we have applied another method to analyse this antenna and verify the above results; HFSS software based on Finite Element Method (FEM). Fig. 7-8 shows the comparison results between both methods.

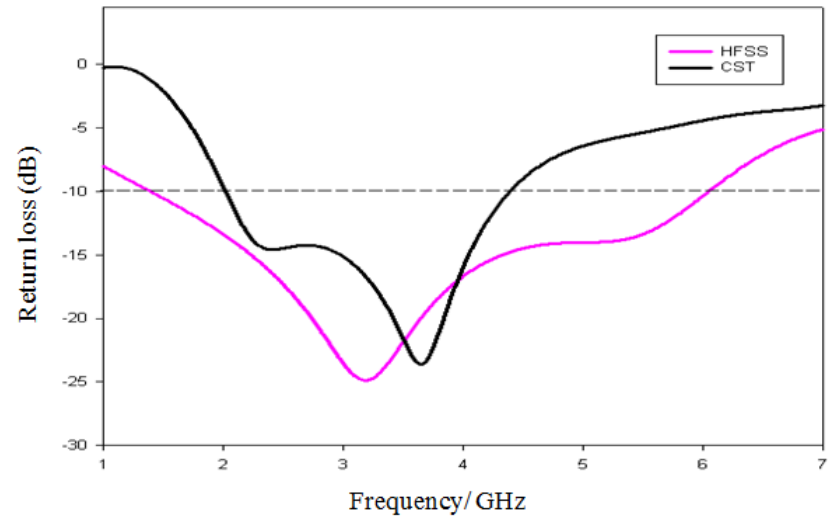

Figure 7. Return loss of the proposed antenna with CST\&HFSS.

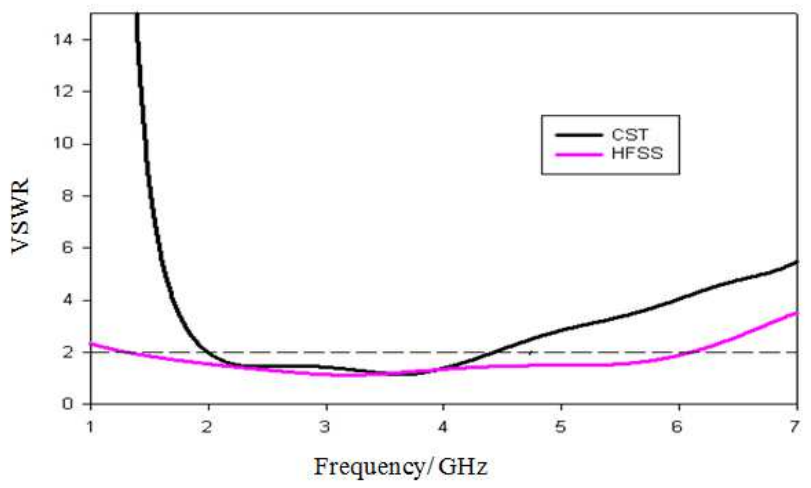

Figure 8. VSWR of the proposed antenna with CST\&HFSS.

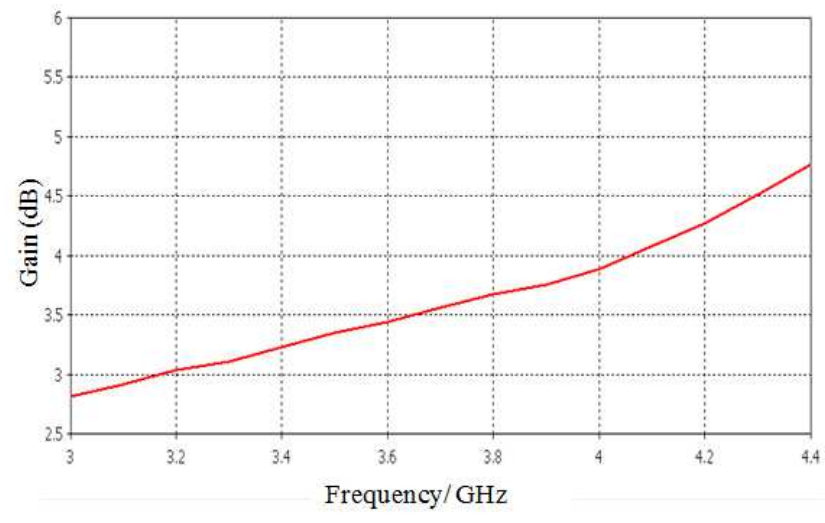

Figure 9. Simulated antenna gain versus frequency.

Fig. 9 presents the gain variation of the proposed antenna that is almost around $3.5 \mathrm{~dB}$ in the frequency range below 3.6 $\mathrm{GHz}$. Then this antenna is suitable for Microwave imaging and Breast Cancer Detection using microwave radiometer, 
also other S-Band applications due to its enhanced bandwidth and the constant gain over its whole frequency band, with some further optimization and manufacturing aspect, this antenna can serve in several UWB applications.

Further Fig. 10 shows the far-field radiation patterns of the proposed antenna at $3.64 \mathrm{GHz}$ in E-plane and H-plane. It can be seen that in the H-plane, the antenna has fairly good omnidirectional radiation pattern. The radiation patterns in the E-plane are like a small dipole leading to bidirectional patterns in the very wide frequency band.

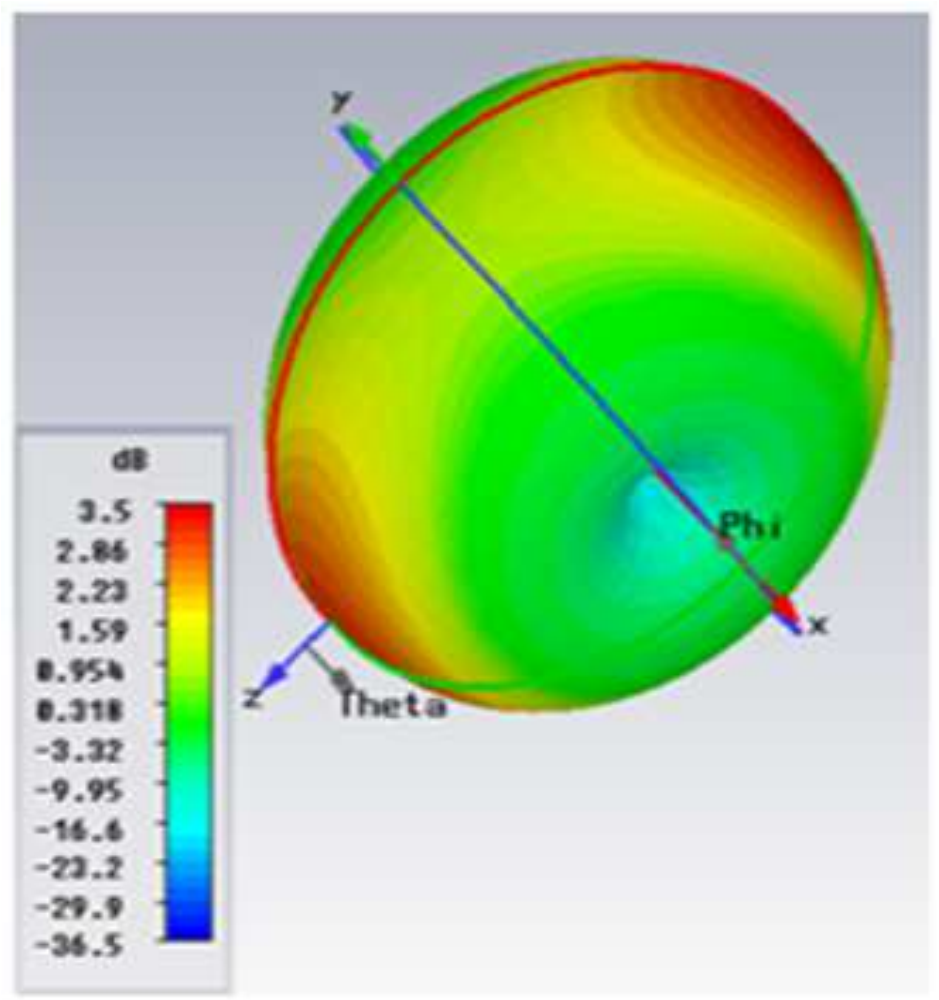

(a)

\section{Farfield Gain Abs (Phi $=0)$}

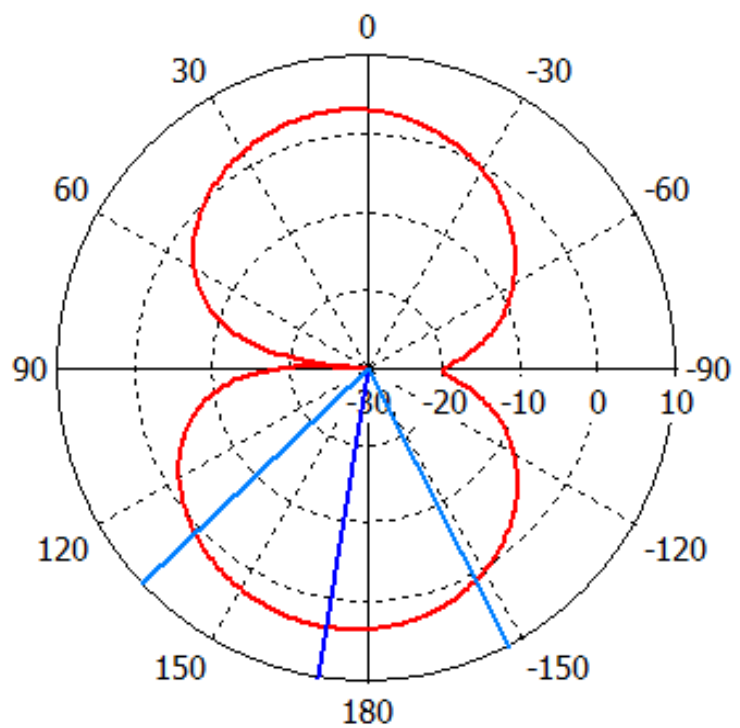

Theta / Degree vs. dB
Farfield Gain Abs (Theta $=0)$

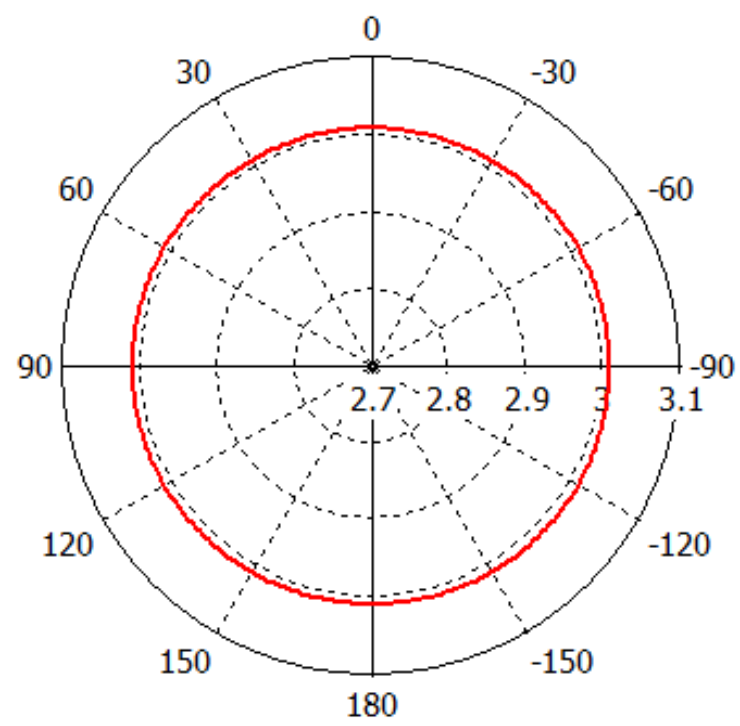

Phi / Degree vs. dB

(b)

(c)

Figure 10. (a) $3 D$ view radiation pattern of the proposed antenna, $2 D$ radiation pattern (b) E-plane, (c): H-plane. 


\section{Comparative Study}

Fig.11 presents a comparison between the performances of some recently developed miniaturized antennas, printed on a
FR4 substrate, and the proposed antenna. Compared with the other structures, the proposed antenna shows a wide impedance bandwidth around S-band (2-4GHz: Framed zones), a compact size, and a less complicated design.
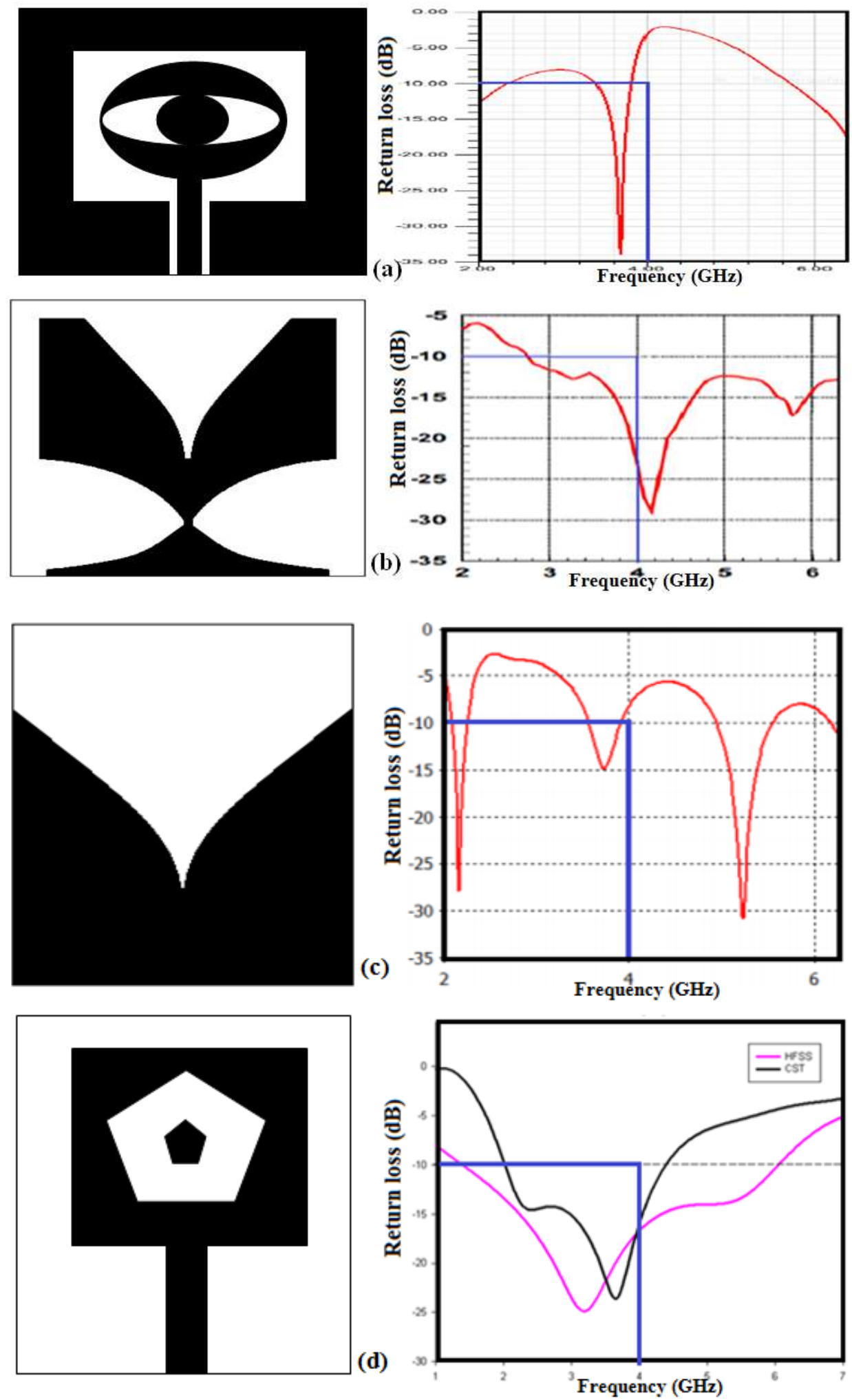

Figure 11. (a), (b), and (c) respectively from [28], [29], and [30], (d) The proposed antenna. 


\section{Conclusion}

In this paper, a miniature microstrip UWB antenna for application in medical imaging is proposed. The antenna satisfactorily meets the requirements and has an UWB attitude. Indeed, the simulated results show that the antenna has a reflection coefficient of $-10 \mathrm{~dB}$ from about $1.3 \mathrm{GHz}$ to 6 $\mathrm{GHz}$ in HFSS software and from $2.01 \mathrm{GHz}$ to $4.4 \mathrm{GHz}$ in CST with all desired UWB radiation characteristics. It has good stability over the entire frequency band provided and that in the two principal planes $\mathrm{E}$ and $\mathrm{H}$. Also the gain is good and suitable for our intended application. Due to its excellent characteristics, this simple low profile antenna structure might be a good candidate for a microwave thermography system or a microwave radiometer for early detection of malignant tumors. Furthermore these attributes makes the proposed antenna very suitable for UWB wireless systems that require low-profile antennas. Future research will systematically focus in evaluating this antenna under various parametric and experimental conditions.

\section{Acknowledgement}

The authors would like to thank the contribution of the professor Abdelhamid Errachid from Institute of Analytic Sciences (ISA) of Lyon University in France and all members of LGE laboratory of ENSET/ENSIAS, Rabat in Morocco for their technical and financial support in this research.

\section{References}

[1] Globocan, "Cancer Incidence, Mortality and Prevalence Worldwide", IARC Cancer Base No. 5. Version 2.0, IARC Press, Lyon, 2004.

[2] Poplack S. P., Paulsen K. D., Hartov A., Meaney P. M., et all., (2004), "Electromagnetic breast imaging: average tissue property values in women with negative clinical findings", Radiology, 571-580.

[3] Wellman P. S., Dalton E. P., Krag D., Kern K. A., Howe R. D., "Tactile imaging of breast masses (2001) Archives of Surgery", 136, 204-208.

[4] Weber G, "Using tactile images to differentiate breast tissue types, thesis", http://www.griffinweber.com.

[5] Soares D., Johnson P., (2007) "Breast imaging update West Indian", 56 940, 351-354.

[6] Yodh A. G, Chance B., (2006) "In vivo continuous-wave optical breast imaging enhanced with indocyanine green Med". Phys. 30, 6, 1039-1047.

[7] RTM (1990) Radiometry Doctor Manual, RTM, Moscow.

[8] Kasabegoudar, V. G., Vinoy, K. J., "Coplanar capacitively coupled probe fed microstrip antennas for wideband applications". IEEE Trans. Antennas Propagat. 58 (10), 3131$3138,2010$.
[9] Gao, S. C., Li, L.W. Leong, M. S., Ye o, T. S., "Wide-band microstrip antenna with an H-shaped coupling aperture", IEEE Trans. Ve h.Tech.51 (1), 17-27, 2002.

[10] Sharma, A. K., Reddy, B .V. R., Mittal, A., "Slot loaded microstrip patch antenna for WLAN and WiMax applications", IEEE International Conference on Computational Intelligence and Communication Technology (CICT), 2015, pp. 597-599.

[11] Ahsan, M. R., Islam, M., Ullah, M., "Computational and experimental analysis of high gain antenna for WLAN/WiMAX applications", 14, 634-641, (2015).

[12] Yongtao, J., Yi ng, L., Shuxi, G., "Slot-coupled broadband patch antenna", Electron. Lett. 51, 445-447 (2015).

[13] Deshmukh, A. A., R ay, K. P. "Broadband proximity-fed square-ring microstrip antennas", IEEE Antennas Propagat. Mag.56, 89-107, 2014.

[14] Chen, Y., Ya ng, S., Nie, Z., "Bandwidth enhancement method for low profile E-shaped microstrip patch antennas", IEEE Trans. Antennas Propagat. 58 (7), 2442-2447, 2010.

[15] Liu, J., Z heng, S., Li, Y., Long, Y., "Broadband monopolar microstrip patch antenna with shorting vias and coupled ring", IEEE Antennas Wirel. Propagat. Lett. 13, 39-42, 2014.

[16] Serrao, J., Fa kih, A., "Design and analysis of a broadband low profile monopolar patch antenna. In: Proceedings", 6th International Conference on Computational Intelligence and Communication Networks, 2014, pp. 46-50.

[17] Sheta, A. F., Mohra, A., Mahmoud, S. F., "Multi-band operation of a compact H-shaped microstrip antenna", Microw. Opt. Lett 35 (5), 363-367, 2002.

[18] Hang, W., L in, Q. W., Lai, H. W., Z hang, X. Y. "Substrate integrated meandering probe-fed patch antennas for wideband wireless devices", IEEE Trans. Compon. Packag. Manufact. Technol.5, 381-388, 2015.

[19] Islam, M. T., Shakib, M. N., Misran, N., "Broadband E-H shaped microstrip patch antenna for wireless systems", Progress Electromagn. Res.98, 163-173, 2009.

[20] Shakib, M. N., Islam, M. T., Misran, N., "High gain W-shaped microstrip patch antenna. IEICE Electro. Exp. Lett. 7, 15461551,2010

[21] Chair, R., Mak, C. L. Lee, K. F., L uk, K. M., Kishk, A. A., "Miniature wide-band half U-slot and half E-shaped patch antennas", IEEE Trans. Antennas Propaga t. 53 (8), 2645$2652,2005$.

[22] Namin, F., Spence, T. G., Werner, D. H., Semouchkina, E., "Broad-band miniaturized stacked-patch antennas for L-band operation based on magneto-dielectric substrates", IEEE Trans. Antennas Propagat. 58 (9), 2817-2822, 2010.

[23] Herscovici, N., "A wide-band single-layer patch antenna", IEEE Trans. Antennas Propaga t. 46, 471-474, 1998.

[24] Luk, K. M., Mak, C. L. Chow, Y. L., Lee, K. F., "Broadband microstrip antenna", Electron. Lett. 34, 1442-1443, 1998.

[25] Chen, Z. N., Chia, M. Y. W., "Broadband rectangular slotted plate antenna", IEEE International Symposium on Antennas and Propagation, July 16-21, 2000.

[26] Computer Simulation Technology: www.cst.com. 
[27] Ansoft High Frequency Structure Simulation (HFSS), Ver. 10, Ansoft Corporation, 2005.

[28] Kirti Vyas, A. K. Sharma, P. K. Singhal, “A Novel CPW Fed Multiband Circular Microstrip Patch Antenna for Wireless Applications", International Conference on Computational Intelligence and Communication Networks, 2012.

[29] Wee Chang Khor, Marek E. Bialkowski, Amin Abosh,
Norhudah Seman and Stuart Crozier, "An Ultra Wideband Microwave Imaging System for Breast Cancer Detection", International Symposium on Antennas and Propagation, ISAP 2006.

[30] Haoyu Zhang, Brian Flynn, Ahmet T. Erdogan, Tughrul Arslan, "Microwave Imaging for Brain Tumour Detection Using an UWB Vivaldi Antenna Array", Loughborough Antennas and Propagation Conference, 2012. 